\title{
Comparative Physiological and Molecular Study of Some Sheep Breeds in Saudi Arabia
}

\author{
${ }^{1}$ Mohammad S. AL-Harbi, ${ }^{1}$ Hamed S. Alwagdany and ${ }^{1,2}$ Sayed A.M. Amer \\ ${ }^{1}$ Department of Biology, Faculty of Science, Taif University, Taif, 888, Saudi Arabia \\ ${ }^{2}$ Department of Zoology, Faculty of Science, Cairo University, Giza, Egypt
}

Received 2013-05-07, Revised 2013-05-17; Accepted 2013-06-06

\begin{abstract}
Naemi, Heri, Najdi and Sawakni sheep breeds inhabiting Kingdom of Saudi Arabia were studied on both physiological and molecular bases. Native polyacrylamide gel-electrophoreses for two enzymes Malate Dehydrogenase $(M d h)$ and Malic Enzyme $(M e)$ recorded 5 isoenzyme loci from which 4 were polymorphic and 1 was monomorphic. Mdh showed three fractions, the first was recorded in Sawakni and Najdi breeds, the second was monomorphic and was recorded in all breeds while the third was recorded in all except Heri. Malic enzyme showed two polymorphic fractions, the first was recorded in Heri and Naemi and the second was recorded in all breeds. Both metabolic enzymes activities were higher in Sawakni than in the native breeds. 607, 227, 498 and 595 bp nucleotides from CO1, ND4, cytb genes and d-loop, respectively, were sequenced with no base substitutions among and/or within breeds except for ND4 gene and d-loop. The molecular tree clustered the three breeds other than Naemi in one group and Naemi was basal. Isoenzymes therefore, discriminate clearly the studied breeds although they are not as accurate as molecular tools indicating their applicability with more efficiency in physiology than in genetics while the d-loop was efficient in discriminating the studied breeds phynotypically.
\end{abstract}

Keywords: Sheep Breeds, Isoenzymes, Mitochondrial DNA, Control Region

\section{INTRODUCTION}

Southwest Asia is considered as one of three main areas in which domestication is believed to be occurred very early (Bruford et al., 2003) and domestic sheep (Ovis aries) were among the first domesticated animals. In Saudi Arabia, Naemi, Heri, Najdi and Sawakni breeds are well identified among many local and introduced breeds. The first three are inhabiting the Arabian Peninsula while the fourth one might be introduced from Sudan.

Naemi breed is also called the desert Awassi sheep in Saudi Arabia (Synnot, 1990). Awassi is a local sheep breed from southwest Asia that originated in the SyrianArabian desert (Epstein, 1985). Heri breed is related to harat of volcanoes of the north west of Arabian Peninsula. It distributes commonly in different areas of Saudi Arabia mainly Qassim, Hejaz plains, Tehama and Corresponding Author: Sayed A.M. Amer, Department of Biology, Faculty of Science, Taif University, Taif, P.O. 888, Saudi Arabia

Sarawat mountains. Najdi is a well adapted multipurpose breed, used for meat, milk and wool production. Najdi has some unique features such as black hair coat with white head, convex head profile and large, pendulous ears (Pritchard et al., 1977), long legs and fat tailed with coarse fleece (Ali and Al-Noami, 1992). Sawakni is a popular breed imported to the Kingdom from Sudan and thus it is not native to Arabia. This breed is named Sawakni because Sudanese live sheep and sheep meat is recognized in Saudi Arabia markets as 'Swakni'. It might be the desert Sheep of North Africa and the Horn of Africa (El-Dirani et al., 2009).

Electrophoretic studies were done extensively on the different tissues of various animals from which it reveals that the enzyme exits in multi molecular forms and functions (Markert and Moller, 1959). Malate dehydrogenase is considered as one of the most extensively studied isozyme systems (Lagana et al., 
2006). This enzyme with lactate dehydrogenase, are very suitable systems for studying several metabolic, genetic, ecological features and they are very useful in systematic studies (Almeida-Val et al., 1992). Malate dehydrogenase and malic enzme are different enzymatically and structurally (Shows et al., 1970). Malate dehydrogenase catalyzes the transformation of malate to oxaloacetate (Zhao et al., 2010), while malic enzyme reversibly catalyzes the oxidative decarboxylation of malate and is a link between the glycolytic pathway and the citric acid cycle (Shows et al., 1970; Song et al., 2001). Both enzymes are important for the NADPH production in ruminants (Laliotis et al., 2010). Malic enzyme is thought to be a key enzyme in lipid biosynthesis.

A breed is defined as "a subspecific group of domestic livestock with definable and identifiable external characteristics that enable it to be separated by visual appraisal from other similarly defined groups within the same species (Scherf, 2000). In sheep, RAPD technique was used to estimate the genetic variation among and within breeds (Paiva et al., 2005). The complete mitochondrial genome of sheep was also sequenced and used for the same purpose (Hiendleder et al., 1998). Length of the strands can vary because of different number of $75 \mathrm{bp}$ long tandem repeats which contain two octamer sequences of mirror symmetry (Hiendleder et al., 1998). Two different regions, control (CR or d-loop) region (Bruford and Townsend, 2006) and NADH Dehydrogenase subunit 4 (ND4) gene (Guo et al., 2005) of mt DNA were used for analyzing the haplogroup frequency of the breeds.

The present study aimed to investigate the biochemical patterns of some isoenzymes related to energy metabolism and the molecular characterization of some mitochondrial DNA fragments related to energy metabolism and phenotypic variation. It also aimed to check whether these biochemical and molecular variability are correlated to physiological performance of these breeds or not?

\section{MATERIALS AND METHODS}

\subsection{Animals}

Twenty three individuals of Naemi, Heri, Najdi and Sawakni sheep breeds from local market of Taif province, Kingdom of Saudi Arabia were used in this study. Blood samples were withdrawn from the jugular vein into heparinized tubes. $300 \mu \mathrm{L}$ were frozen for the molecular study. The rest of the blood samples were immediately centrifuged at $3000 \mathrm{rpm}$ for 3 5 min and the plasma were decanted for isoenzymatic analyses.

\subsection{Isoenzymes}

The isoenzymes were separated in $10 \%$ polyacrylamide gel electrophoresis according to (Stegemann et al., 1985) as follows. A volume of $40 \mu \mathrm{L}$ plasma was mixed with $20 \mu \mathrm{l}$ sucrose and $10 \mu$ bromophenol blue, then a volume of $50 \mu \mathrm{L}$ from this mixture was applied to each well. For Malate Dehydrogenase (Mdh) (EC 1.1.1.37), the gel was soaked in $100 \mathrm{ml}$ of $0.05 \mathrm{M}$ Tris $\mathrm{HCl} \mathrm{pH} 8.5$ containing $25 \mathrm{mg}$ NBT, $25 \mathrm{mg}$ EDTA, $25 \mathrm{mg}$ NAD, $10 \mathrm{mg}$ malic acid and $3 \mathrm{mg}$ PMS (Wendel and Weeden, 1990). For Malic enzyme $(\mathrm{Me})$ (EC 1.1.1.40), the gel was soaked in 100 $\mathrm{ml}$ of $0.05 \mathrm{M}$ Tris $\mathrm{HCl} \mathrm{pH} 8.5$ containing $25 \mathrm{mg}$ NBT, 25 mg EDTA, $25 \mathrm{mg}$ NADP, $10 \mathrm{mg}$ malic acid, $100 \mathrm{MgCl} 2$ and PMS (Wendel and Weeden, 1990). The gel was kept in a fixative solution (ethanol and $20 \%$ glacial acetic acid, 9: $11 \mathrm{v} / \mathrm{v}$ ) for $24 \mathrm{~h}$ and then was photographed.

\subsection{DNA Extraction and PCR Experiments}

Mitochondrial DNA was extracted from $0.5 \mathrm{~mL}$ blood samples with QIAGEN spin-column kits according to the manufactur's instruction. PCR was conducted in a final volume of $25 \mu \mathrm{L}$ containing $1 \mu \mathrm{L}$ DNA template, $0.1 \mu \mathrm{L}$ of 10 Pmolar forward primer, $0.1 \mu \mathrm{L}$ of 10 Pmolar reverse primer of the corresponding genes (Table 1), 12.5 $\mu \mathrm{L}$ PCR master mix (Promega Corporation, Madison, WI) and $11.3 \mu \mathrm{L}$ autoclaved deionized distilled water. PCR was carried out using a PeX 0.5 thermal Cycler with the cycle sequence at $94^{\circ} \mathrm{C}$ for $4 \mathrm{~min}$ one cycle, followed by 40 cycles each of which consisted of denaturation at $94^{\circ} \mathrm{C}$ for one min, annealing at corresponding specific temperature (Table 1) for one min and extension at $72^{\circ} \mathrm{C}$ for one min with a final strand elongation for one cycle at $72^{\circ} \mathrm{C}$ was done for an additional $5 \mathrm{~min}$. The PCR products were analyzed in $1 \%$ agarose gel electrophoresis in TAE buffer $(40 \mathrm{~mm}$ Tris, $40 \mathrm{mM}$ acetic acid and 1mM EDTA) with ethidium bromide staining. A 100-bp DNA ladder (Biolabs) was used as a molecular marker. Then PCR products were visualized under UV light and photographed. The PCR products were then excised from agarose gels and purified using spin column (BioFlux, Tokyo) according to the manufacturer instructions.

\subsection{Sequencing}

The purified PCR products were sequenced in an ABI PRISM $3730 \mu \mathrm{L}$ sequencer (Applied BioSystems) and BigDyeTM Terminator Sequencing Kits with AmpliTaqDNA polymerase (FS enzyme) (Applied Biosystems) following the protocols supplied by the manufacturer. 
Mohammad S. AL-Harbi et al. / American Journal of Biochemistry and Biotechnology 9 (2): 183-194, 2013

Table 1. Primers designed and used for PCR amplification and sequencing. Annealing temperature refers to that of the conducted PCR to obtain the amplified fragments

\begin{tabular}{|c|c|c|c|c|}
\hline Gene & Primer name & Sequence $\left(5^{`}-3^{`}\right)$ & Annealing temperature $\left({ }^{\circ} \mathrm{C}\right)$ & Scource \\
\hline \multirow[t]{2}{*}{$\overline{\mathrm{CO} 1}$} & Ovis CO1-F & GCTGGTATCACAATACTACT & 56 & This study \\
\hline & Ovis $\mathrm{CO} 1-\mathrm{R}$ & TAGTCCTAGGAAATGCTGTG & & \\
\hline \multirow[t]{2}{*}{ ND4 } & Forward -OV11 & GAC TCC ACC TCT GAC TTC C & 57 & Yuncu (2009) \\
\hline & Reverse -OV11 & TGA ATG AGA ATG GCA ACA & & \\
\hline \multirow[t]{2}{*}{ cytb } & Ovis cytb-F & AGGCCTATTCCTAGCAATAC & 56 & This study \\
\hline & Ovis cytb-R & TAGTAGCATGGCGCCTAAG & & \\
\hline d-loop & $\begin{array}{l}\text { Ovis d-loop-F } \\
\text { Ovis d-loop-R }\end{array}$ & $\begin{array}{l}\text { CGG ACA TGA GCG TTC ATA AAC } \\
\text { GGA TGC TCA AGA TGC AGT TA }\end{array}$ & 57 & This study \\
\hline
\end{tabular}

After reading the targeted genes, the nucleotide sequences have been treated with different software programs (DNASIS, MacClade and PAUP) that enabled to detect genetic relatedness between different samples and breeds. The sequenced genes were tested by BLAST program to check their relatedness to the sequenced genes for sheep in the Genbank database. The same published genes for both sheep and goat were taken from the Genbank with their accession numbers (JN632608, NC-009849, NC-009628, respectively) for the necessary alignments and tree construction.

\subsection{Statistical Analyses}

The isoenzymatic data were subjected to Student ttest in SPSS package to examine the significance level between each two breeds. The obtained DNA sequences were aligned separately and manually using MacClade v.4. The unalignable and gap-containing sites were deleted and the aligned data were then concatenated so that $1900 \mathrm{bp}$ were left for the analyses. The tree analyses were done by Maximum-Parsimony (MP) and NeighborJoining (NJ) methods with PAUP* 4.0b10 (Swofford, 2002) by heuristic searches with the TBR branch swapping and 10 random taxon additions, respectively. The bootstrapping replicates were set to be 1000 with simple additions for the two methods.

\section{RESULTS}

Native polyacrylamide gel-electrophoreses for two enzymes (malate dehydrogenase and malic enzyme) recorded 5 isoenzyme loci from which 4 were polymorphic and 1 was monomorphic. Some of these loci exhibited high activity (shown as thick and dark bands) while others were very thin exhibiting low activity.

$M d h$ showed three fractions in the electrophoretic pattern (Fig. 1). The first fraction $(M d h-1)$ was recorded in Sawakni and Najdi breeds only. The second fraction was monomorphic and was recorded in all breeds, while the third was recorded in all breeds except Heri. Table 2 showed the means and standard errors for the percentage amount of the studied isoenzymes in the different sheep breeds. Mdh-2 isoform showed a significant increase $(p<0.05)$ in its activity in Heri than in Najdi. The total enzyme was significantly higher in Sawakni $(\mathrm{p}<0.01, \mathrm{p}<0.05)$ than in Heri and Naemi breeds, respectively. The mean fractional activity of the total enzyme was $27.32 \pm 1.94$ in Sawakni, 16.38 \pm 0.91 in Heri and $17.72 \pm 1.72$ in Naemi.

Malic enzyme showed two polymorphic fractions in the electrophoretic pattern (Fig. 2). The first fraction $(\mathrm{Me}-1)$ was recorded in Heri and Naemi breeds only. The second fraction was recorded in all breeds but some samples within breeds did not show this locus. Table 3 showed the means and standard errors for the percentage amount of the studied isoenzymes in different sheep breeds. $M e-2$ isoform showed a significant fractional activity increase $(S<0.05)$ in Naemi than in Najdi. The mean fractional activity of this isoform was $7.31 \pm 0.84$ in Naemi and $3.00 \pm 0.82$ in Najdi. The mean fractional activity of the total enzyme was significantly higher in Heri and Naemi breeds than in the Sawakni $(p<0.01$, $\mathrm{p}<0.05)$ and Najdi $(\mathrm{p}<0.05, \mathrm{p}<0.05)$ breeds, respectively. The mean values of the total enzyme activity were $16.9 \pm 2.54$ in Heri, $19.47 \pm 2.29$ in Naemi, 3.30 \pm .767 in Sawakni and $5.67 \pm 1.40$ in Najdi.

Unambiguous nucleotides of 607 bp, 227 bp, 498 bp and $595 \mathrm{bp}$ from CO1, ND4, cytb genes and non-coding d-loop, respectively were sequenced for at least three samples from each breed. These data were deposited in NCBI GenBank database with their accession numbers (KC669571-KC669595) for CO1 and d-loop and (KC689756- KC689785) for cytb and ND4 genes. In order to estimate the base composition and frequencies for the obtained sequences, the data were concatenated and the gab-containing sites were deleted except for the d-loop so that $1900 \mathrm{bp}$ were left for analysis. The data showed base frequencies of $\mathrm{A}=30.2 \%, \mathrm{C}=23.8 \%, \mathrm{G}=15.8 \%$ and $\mathrm{T}=$ $30.2 \%$ of the 1900 nucleotides used for tree analyses, 1675 were constant and 225 were variables. 
Table 2. Mean \pm SE of the percentage amount for the studied malate dehydrogenase isoenzymes $(M d h)$ in plasma of different sheep breeds. The significant level was estimated by Student t- test. * = significant level between Heri and Najdi, $+=$ significant level between Heri and Sawakni, $\mathrm{x}=$ significant level between Naemi and Sawakni

\begin{tabular}{llllrc}
\hline Enzyme & Isoform (locus) & Heri & Naemi & Sawakni & Najdi \\
\hline$M d h$ & 3 & - & $5.28 \pm 1.49$ & $4.68 \pm 0.09$ & $6.51 \pm 0.880$ \\
& 2 & $16.29 \pm 0911$ & $13.76 \pm 0.55$ & $15.23 \pm 0.89$ & $4.68 \pm 0.090$ \\
& 1 & -- & -- & $6.88 \pm 0.53$ & $5.96 \pm 0.620$ \\
& Total & $16.38 \pm .911$ & $17.72 \pm 1.72$ & $27.32 \pm 1.94^{++, \mathrm{x}}$ & $21.35 \pm 1.29$ \\
\hline
\end{tabular}

Table 3. Mean \pm SE of the percentage amount for the studied malic enzyme $(M e)$ in plasma of different sheep breeds. The significance level was estimated by Student t-test. * = significant level between Heri and Najdi, $+=$ significant level between Heri and Sawakni, $\mathrm{x}=$ significant level between Naemi and Sawakni, = = significant level between Naemi and Najdi

\begin{tabular}{llllll}
\hline Enzyme & Isoform (locus) & Heri & Naemi & Sawakni & Najdi \\
\hline$M e$ & 2 & $4.40 \pm .911$ & $7.31 \pm 0.84$ & $3.30 \pm 0.76$ & $3.00 \pm 0.82^{\bullet}$ \\
& 1 & $14.25 \pm 1.92$ & $12.15 \pm 1.82$ & -- & -- \\
& Total & $16.9 \pm 2.54$ & $19.47 \pm 2.29$ & $3.30 \pm .767^{++, x}$ & $5.67 \pm 1.40^{*,-}$ \\
\hline
\end{tabular}

Table 4. Pairwise genetic distance among the different sheep breeds. These distances were estimated from the sequenced data in this study. The bolded values refer to the distances within breeds

\begin{tabular}{lllll}
\hline Breed & Heri & Najdi & Naemi & Sawakni \\
\hline Heri & 0.0016 & & & \\
Najdi & 0.0050 & 0.0064 & & \\
Naemi & 0.0150 & 0.0169 & 0.0042 & \\
Sawakni & 0.0045 & 0.0066 & 0.0153 & 0.0032 \\
\hline
\end{tabular}

About 190 of the variable sites were parsimonyuninformative and 35 were informative under parsimony criterion. The tree that has been constructed showed consistency index $(\mathrm{CI}=0.993)$, homology index $(\mathrm{HI}=$ $0.007)$, retention index $(\mathrm{RI}=0.956)$ and rescaled consistency index $(\mathrm{RC}=0.949)$.

Single neighbor-joining tree (Fig. 3) was obtained from all data sets with reasonable statistical supports for two computational methods (MP and NJ). The tree showed clustering of each breed with each other except for Najdi which showed close and/or mixed relationship with Heri. Heri, Najdi and Sawakni breeds clustered in one group with strong bootstrapping (100 BP for both MP and NJ methods). Naemi breed came basal to all breeds studied. As shown in Table 4, the genetic distance showed the smallest values within each breed $(0.0016,0.0042,0.0064$ and 0.0032 for Heri, Naemi, Najdi and Sawakni breeds, respectively) except for Najdi where the smallest distance was found between this breed and Heri $(\mathrm{D}=0.005)$. The tree topology also mixed Najdi with Heri. The interpretation of this mixing maybe attributed to the small sampling size or possible hybridization between these two breeds.

For the protein-coding ND4 gene that codes for NADH dehydrogenase subunit 4, 227 bp were sequenced for different samples. The complete length of this mitochondrial gene in $O$. aries is $1378 \mathrm{bp}$ as deposited in the Genbank database. Based on the alignment, the sequenced fragment is located between base 648 and base 874 . The 227 bp showed 4 base substitutions among and within breeds (Fig. 4). All these substitutions were transitions (purines to purines and pyrimidines to pyrimidines). The mutations occurred among all samples either interspecific or intraspecific were in the third position with no amino acids changes. The synonymous changes involved substitutions of adinine with guanine at $\mathrm{G}_{678} \rightarrow \mathrm{A}_{678}$, adinine with guanine at $\mathrm{G}_{750} \rightarrow \mathrm{A}_{750}$, thymine with cytosine at $\mathrm{T}_{768} \rightarrow$ $\mathrm{C}_{768}$ and gaunine with adenine at $\mathrm{G}_{849} \rightarrow \mathrm{A}_{849}$. The numbers below the base letters referred to the exact position of this base inside the complete gene sequence.

Approximately $585 \mathrm{bp}$ of the mitochondrial d-loop region were sequenced for three individuals from each of the sheep breeds. The electropherogram of the obtained sequence for the individuals from the same breed were compared and when a bias was found, the most like base was considered (data not shown). The alignment of this fragment with its counterpart of other sheep breeds published in the Genbank indicated that this fragment is located between 15769 and 16287 of the complete dloop. The complete d-loop of sheep is $1180 \mathrm{bp}$ long, with four or three copies of repeated $75 \mathrm{bp}$ motif in the tRNAPro proximal part. The sequenced fragment of the four breeds herein showed approximately these three motifs (Fig. 5). These repeats contain strong stem-and-loop 40 bp (Fig. 6) secondary structure. Sixteen nucleotides of the repeat are two octamer sequences of mirror symmetry (TTAATGTA, TACATTAA) forming the stable stem. In between this stem, there is a loop of $24 \mathrm{bp}$. All sheep breeds posses two motifs located immediately upstream of this repeat discriminating two haplotypes which are G/ACCCC (haplotype A) and ACCC/TC (haplotype B). 


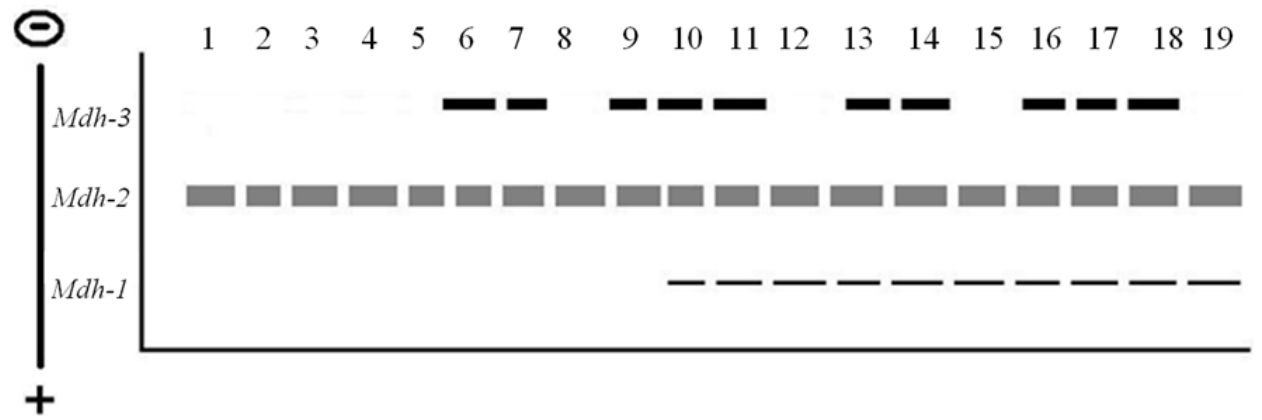

Fig. 1. The electrophoretic profile of Mdh isoenzymes in the studied samples. Lanes are as follow: 1-5 (Heri), 6-9 (Naemi), 10-14 (Sawakni) and 15-19 (Najdi)

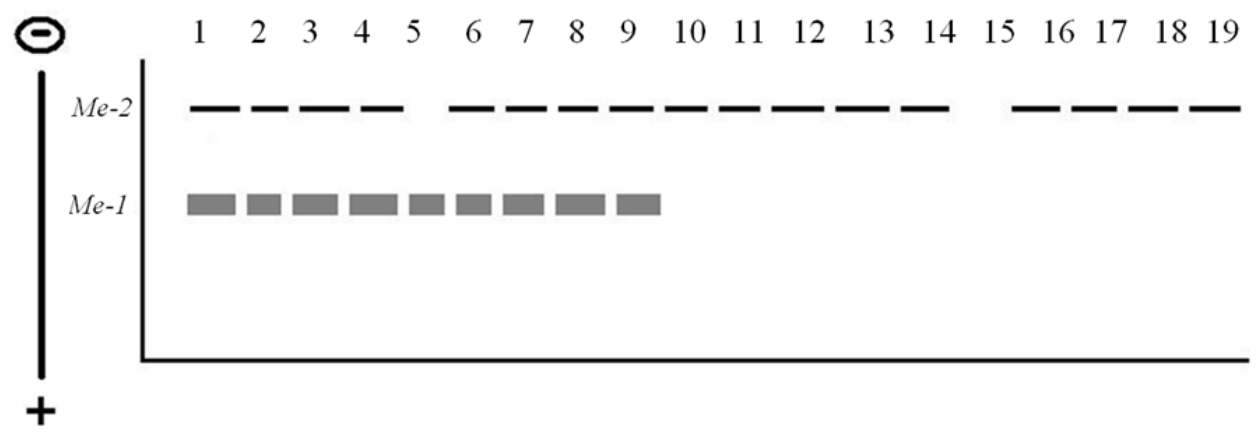

Fig. 2. The electrophoretic profile of $M e$ isoenzymes in the studied samples. Lanes are as follow: 1 - 5 (Heri), 6 - 9 (Naemi), 10 - 14 (Sawakni) and 15 - 19 (Najdi)

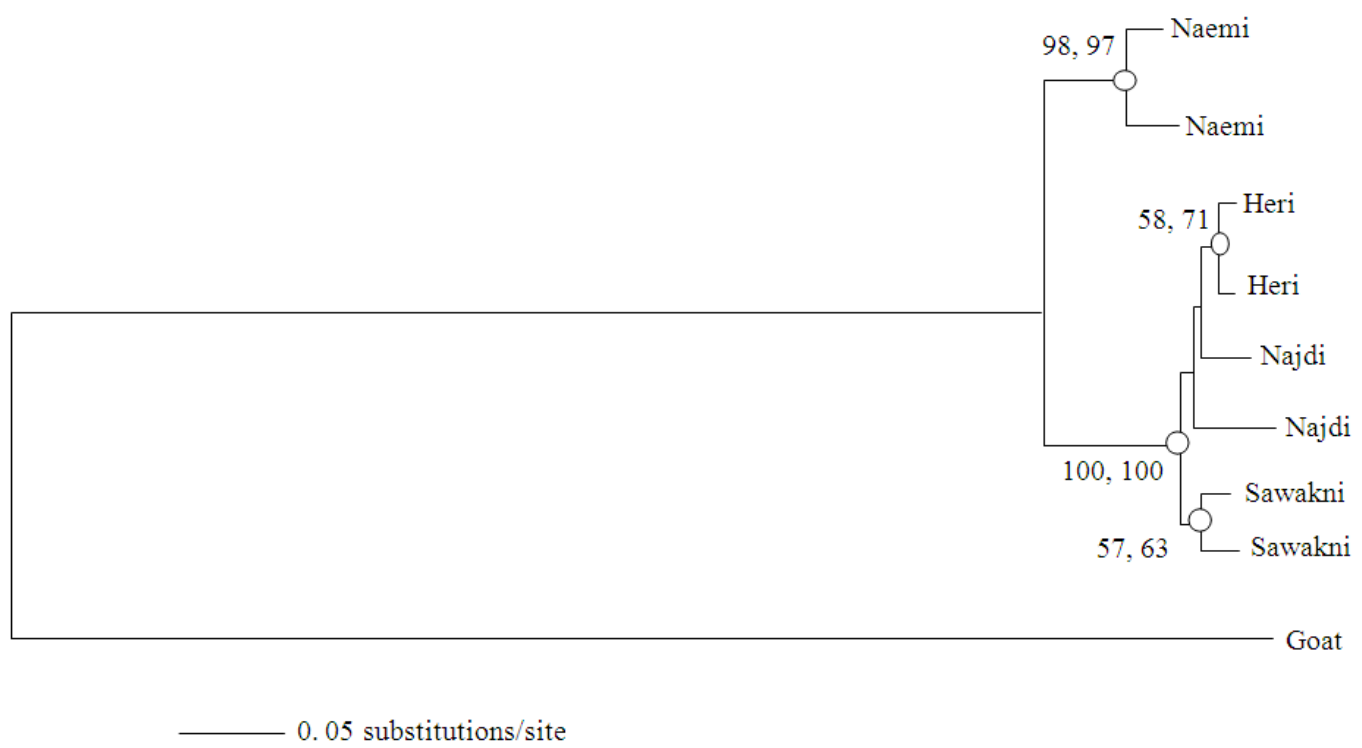

Fig. 3. Neighbor-joining tree constructed from 1900 bp sequenced fragments of CO1, cytb, ND4 genes and d-loop region for the four sheep breeds used in this study. A goat sample represents the ourtgroup of the tree. Values at nodes refer to the bootstrapping of maximum-parsimony and neighbor-joining analyses, respectively. Values were shown when they were over 50\% 
Mohammad S. AL-Harbi et al. / American Journal of Biochemistry and Biotechnology 9 (2): 183-194, 2013

$\begin{array}{lll}\text { Heri } & 1 \\ \text { Heri } & 2 & \\ \text { Heri } & 3 & \\ \text { Najdi } & 1 \\ \text { Najdi } & 2 & \\ \text { Najdi } & 3 & \\ \text { Naemi } & 1 & \\ \text { Naemi } & 2 & \\ \text { Naemi } & 3 & \\ \text { Sawakni } & 1 \\ \text { Sawakni } & 2 \\ \text { Sawakni } & 3 \\ & \\ & \\ \text { Heri } & 1 & \\ \text { Heri } & 2 & \\ \text { Heri } & 3 & \\ \text { Najdi } & 1 & \\ \text { Najdi } & 2 & \\ \text { Najdi } & 3 & \\ \text { Naemi } & 1 & \\ \text { Naemi } & 2 & \\ \text { Naemi } & 3 & \\ \text { Sawakni } & 1 \\ \text { Sawakni } & 2 \\ \text { Sawakni } & 3\end{array}$

\begin{tabular}{|c|c|c|c|c|}
\hline & & & & \\
\hline & САTGTAGAAG & СTCСАATTGC & GFGCTCCATG & GTCCTTGCAG \\
\hline C CCAAAGCC & CATGTAGAAG & СTCCAATTGC & G G TCCATG & GTCCTTGCAG \\
\hline CCCAA.AGCC & CATGTAGAAG & СТCCAATTGC & СТсСА & $\mathrm{GTCCTTGCAG}$ \\
\hline CCAAAGCC & CATGTAGAAG & CTCCAATTGC & СТсСАTG & GTCCTTGCAG \\
\hline$G C C$ & CATG' & & & $I G C A G$ \\
\hline AAAGCC & CATGTAGAAG & СTCCAATTGC & GCTCCATG & GTCCTTGCAG \\
\hline TCCCAAAGCC & СATGTAGAAG & СТССААTTGC & $G C T C C A T G$ & GTCCTTGCAG \\
\hline CCCAAAGCC & CATGTAGAAG & CTCCAATTGC & $\forall G C T C \subset A T G$ & GTCCTTGCAG \\
\hline TCCCAAAGCC & CATGTAGAAG & СТCCAATTGC & GCTCCATG & $\mathrm{GTCCTTGCAG}$ \\
\hline CCCAAAGCC & CATGTAGAAG & CTCCAATTGC & $G \subset T C C A T G$ & GTCCTTGCAG \\
\hline CCAAAGCC & CATGTAGAAG & СТССААТTС & GCTCCATG & GTCCTTGCAG \\
\hline CAAAGCO & САTGTAGAAG & СТССААTGC & & \\
\hline
\end{tabular}

ATGAGGCATA ATCATHACCA GCTCMATTTG CCTTCGCCAa ATGAGGCATA ATCATAACCA GCTCAATTTG CCTTCGCCA ACGGACCTAA ATGAGGCATA ATCATAACCA GCTCAATTG CCTTCGCCA ACGGACCTA ATGAGGCATA ATCATAACCA GCTCAATTT CCTTCGCCA ACGGACCTAA ATGAGGCATA ATCATAACCA GCTCAATTTG CCTTCGCCAA ACGGACCTAA ATGAGGCATA ATCATAACCA GCTCAATTTG CCTTCGCCA ACGGACCTAA ATGAGGCATA ATCATAACCA GCTCAATTTG CCTTCGCCAA ACGGACCTAA ATGAGGCATA ATCATAACCA GCTCAATTTG CCTTCGCCAA ACGGACCTAA ATGAGGCATA ATCATAACCA GCTCAATTT CCTTCGCCAA ACGGACCTAA ATGAGGCATA ATCATAACCA GCTCAATTTG CCTTCGCCAA ACGGACCTAA ATGAGGCATA ATCATAACCA GCTCAATTTG CCTTCGCCA ACGGACCTAA

Heri 1 Heri 2 Heri 3

Fig. 4. The aligned nucleotides of the sequenced ND4 gene for different indivduals of the studied sheep breeds. Note the high identity among the different samples. The letters inside the boxes are polymorphic among indivuduals and/or breeds 
Mohammad S. AL-Harbi et al. / American Journal of Biochemistry and Biotechnology 9 (2): 183-194, 2013

\begin{tabular}{|c|c|c|c|c|c|c|}
\hline & & & & & & 50 \\
\hline Heri & & CATTAATGA & T T TACCT $\subset$ AT & GCATATA GC & ACGTACATAG & TATTAATGTA \\
\hline Heri 2 & & CATTAAATGA & TT TACСTCAT & GCATATAAGC & ACGT ACAT A & TATTAATGTA \\
\hline Najdi & 1 & САTTAАATGA & ТTТАCСТ САT & GCATATAAGC & ACGT ACAT A & TATTAATGTA \\
\hline $\mathrm{Najdi}$ & 3 & CATTGAATGA & ТTTACCT СAT & GCATATAAGC & ACGT ACAT A & TATTAATGTA \\
\hline Naemi & 1 & CATT AАATGA & ТTTACСТ САT & GCGTATAAGC & ACGT ACATAA & TATTAATGTA \\
\hline Naemi & 2 & САTTAАATGA & ТTTACDCCAT & GCGTATAAGC & $A C G T A C A T A A$ & TATTAATGTA \\
\hline Sawakni & & САT TAАAT GA & TTTACCT СAT & GCATATAAGC & ACGTACATAA & TATTAATGTA \\
\hline Sawakni & & CATTAAATGA & TTTACCT САT & GCATATAGGC & ACGTACATAG & TATTAATGTA \\
\hline Heri & & ATATAG & TTATATGTAT & AAAGTACATT & AAATGATTTA & CCTEATGCAT \\
\hline Heri 2 & & ATAT AGGCCC & TTATATGTAT & AAAGT ACAT T & AАATGATTTA & CCTCATGCAT \\
\hline Najdi & 1 & ATATAGAC-C & TTATATGTAT & AAAGTACAT T & AАATGATTTA & CCCCATGCAT \\
\hline $\mathrm{Najdi}$ & 3 & ATATAGAC-C & TTATATGTAT & AAAGTACAT T & GAATGATTTA & CCCCATGCAT \\
\hline Naemi & 1 & ATATAG --- A & TTATATGTAT & AAAGTACATT & AАATGATTTA & CCTCATGCG T \\
\hline Naemi & 2 & ATATAG --- A & TTATATGTAT & AAAGTACATT T & AAATGATTAA & CCCCATGCGT \\
\hline Sawakni & & AT ATAG GACC & TTATATGTAT & AAAGT ACATT T & AAATGATTTA & CCCCATGCAT \\
\hline Sawakni & & ATATAGGACC & TTATATGTAT & AAAGTACATT & AAATGATTA & CCTCAT GCAT \\
\hline & & ACGTACATAG & TAT TAAT GTA & ATACAGACAT & TATATGTATA & $\begin{array}{r}150 \\
\text { AAGTACATTA }\end{array}$ \\
\hline Heri 2 & & ACGTACATAG & TATTAATGTA & ATATAGACAT & TATATGTATA & AAGTACATTA \\
\hline Najdi & 1 & ACGTACATAG & TAT TAATGTA & ATATAGACAT & TATATGTATA & AAGTACATTA \\
\hline Najdi & 3 & ACGTACATAG & TAT TAATGTA & ATATAGACAT & TATATGTATA & AAGTACATT A \\
\hline Naemi & 1 & ACGTACATAA & TATTAATGTA & ATATAGACAT & TATATGTATA & AAGTACATTA \\
\hline Naemi & 2 & ACGTACATAA & TAT TAAT GTA & ATACAGACAT & TATATGTATA & AAGTACATTA \\
\hline Sawakni & & ACGTACATAA & TATTAATGTA & ATATAGACAT & TATATGTGTA & AAGTACATTA \\
\hline Sawakni & & ACGTACATAG & TAT TAATGTA & ATATAGACAT & TATATGTATA & AAGTACATTA \\
\hline Heri & & AATGATTTAC & gCCATGCATA & TAAGCACGTA & САтАGTАтTA & ATGTAATATA \\
\hline Heri 2 & & AATGATTTAC & dCCATGCAIA & TAAGCACGTA & CATAGTATTA & ATGT AATATA \\
\hline Najdi & 1 & AATGATTCAC & dCCATGCATA & TAAGCACGTA & CATA & ATGT AATATA \\
\hline $\mathrm{Najdi}$ & 3 & AATGATTTAC & dCCATGCATA & TAAGCACGTA & CATAGTATTA & ATGTAATATA \\
\hline Naemi & 1 & AATGATTTAC & qTCATGCGTA & TAAGCACGTA & CATAATATTA & ATGTAATATA \\
\hline Naemi & 2 & AATGATTTAC & dCCATGCGTA & TAAGCACGTA & ГАТТА & ATGTAATATA \\
\hline Sawakni & & AATGATTTAC & वTCATGCATA & TAAGCACGTA & CATAGTATTA & ATGTAATACA \\
\hline Sawakni & & ${ }_{A}^{\text {AATGATTTAC }}$ & QT CATGCATA & TAAGCACGTA & CATAGTATTA & ATGT AATACA \\
\hline Heri & & GACATTATAT & GTATAAAGTA & САT TAAA TGA & TTTACOCCAT & GCATAtAAGC \\
\hline Heri 2 & & GACATTATAT & GTATAAAGTA & CAT TAAATGA & TT TACQCCAT & GCATATAAGC \\
\hline Najdi & 1 & GACATTATAT & GTATAAAGTA & САTTAAGTGA & ТTТАСОТСАТ & GCATATAAGC \\
\hline Najdi & 3 & GACATTATAT & GTATAAAGTA & САT TAAATGA & TTTACDCTAT & GCATATAAGC \\
\hline Naemi & 1 & GACATTATAT & GTATAAAGTA & САTTAAATGA & TTTACOCCAT & GCGTATAGGC \\
\hline Naemi & 2 & GACATTATAT & GTATAAAGTA & САT TAAATGA & TTTACOCCAT & GCGTATAGGC \\
\hline Sawakni & & GACATTATAT & GTATAAAGTA & САT TAAATGA & TTTACDCCAT & GCATATAAGC \\
\hline Sawakni & & GACATTATAT & GTATAAAGTA & CAT TAAGTGA & TT TACQCCAT & GCATATAAGC \\
\hline Heri & & ATGTACATTT & $\mathrm{GT} T \mathrm{~T} C A C T \mathrm{GA}$ & AGCATGTAGG & & GCTTGACCGT \\
\hline Heri 2 & & ATGTACATTT & GT TCACT GA & AGCATGPAGG & GTATTAАACT & GCTTGACCGT \\
\hline Najdi 1 & & ATGTACATTE & GTTTCACTGA & AGCATGTAGG & GTATTAAACT & GCTTGACCGT \\
\hline Najdi & & ATGTACATTT & GTTTCACT GA & AGCATGTAGG & GTATTAAACT & GCTTGACCGT \\
\hline Naemi & 1 & ATGTACATTE & ACTTCACTGA & AGCATATAGG & АСАТTGAАСТ & GCTTGACCGT \\
\hline Naemi 2 & & ATGTACATTT & $\mathrm{ACT} T \mathrm{TACT} G A$ & AGCATATAGG & GCATTGGACT & GCTTGACCGT \\
\hline Sawakni & 1 & ATGTACATTT & GTTTAACT GA & AGCATGTAGG & GTATTAAАCT & GCTTGACCGT \\
\hline Sawakni & 3 & ATGTACATTT & GTTTCACT GA & AGCATGTAGG & GTATTAAACT & GCTTGACCGT \\
\hline Heri & & CATAGTACA & AAA & TCCATTCTAG & TCAACATGOG & TATCQTATCC \\
\hline Heri 2 & & ACATAGTACA & TGAAGTCAAA & TCCATTCTAG & TCAACATGCG & TATCQTATCC \\
\hline Najdi 1 & & ACATAGTACA & TGAAGTCAAA & TCCATTCTAG & TCAACATGQG & TATCOTACCC \\
\hline Najdi & & ACATAGTACA & TGAAGTCAAA & TCCATTCTAG & TCAACATGqG & TATCqTATCC \\
\hline Naemi & & ACATAGTACA & TGAAGTCAAA & TCOGTCCTAG & TCAACATGCA & TATCOTATCC \\
\hline Naemi 2 & & ACATAGTACA & TGAAGTCAAA & TCOGTCCTAG & TCAACATGCA & TATCCCATCC \\
\hline Sawakni & 1 & ACATAGTACA & TGAAGTCAAA & TCCATTCTAG & TCAACATGCG & TATCOTATCC \\
\hline Sawakni & 3 & ACATAGTACA & TGAAGTCAAA & TCCATTCTAG & TCAACATGQG & TATCQTATCC \\
\hline Heri & & ATTAGATCAC & GAGCTTGTTC & ACCATGCCGC & GTGAAACCAA & $\begin{array}{r}400 \\
\text { CAACCCGC TC }\end{array}$ \\
\hline Heri 2 & & ATTAGATCAC & GAGCTTGTTC & ACCATGCCGC & GTGAAACCAA & CAACCCGC TC \\
\hline Najdi 1 & & AT TAGATCAC & GAGCTTGTTC & ACCATGCCGC & GTGAAACCAA & CAACCCGCTC \\
\hline Najdi & 3 & ATTAGATCAC & GAGCTTGT TC & ACCATGCCGC & GTGAAACCAA & CAACCCGCTC \\
\hline Naemi & 1 & ACTAGATCAC & GAGCTTGTTC & ACCATGCCGC & GTGAAACCAA & CAACCCGCTT \\
\hline Naemi & & ACTAGATCAC & GAGCTTGTTC & ACCATGCCGC & GTGAAACCAA & CAACCCGCT T \\
\hline Sawakni & 1 & AT TAGATCAC & GAGCTTGTTC & ACCATGCCGC & GTGAAACCAA & CAACCCGCTC \\
\hline Sawakni & 3 & ATTAGATCAC & GAGCTTGTTC & ACCATGCCGC & GTGAAACCAA & CAACCCGCTC \\
\hline
\end{tabular}


Mohammad S. AL-Harbi et al. / American Journal of Biochemistry and Biotechnology 9 (2): 183-194, 2013

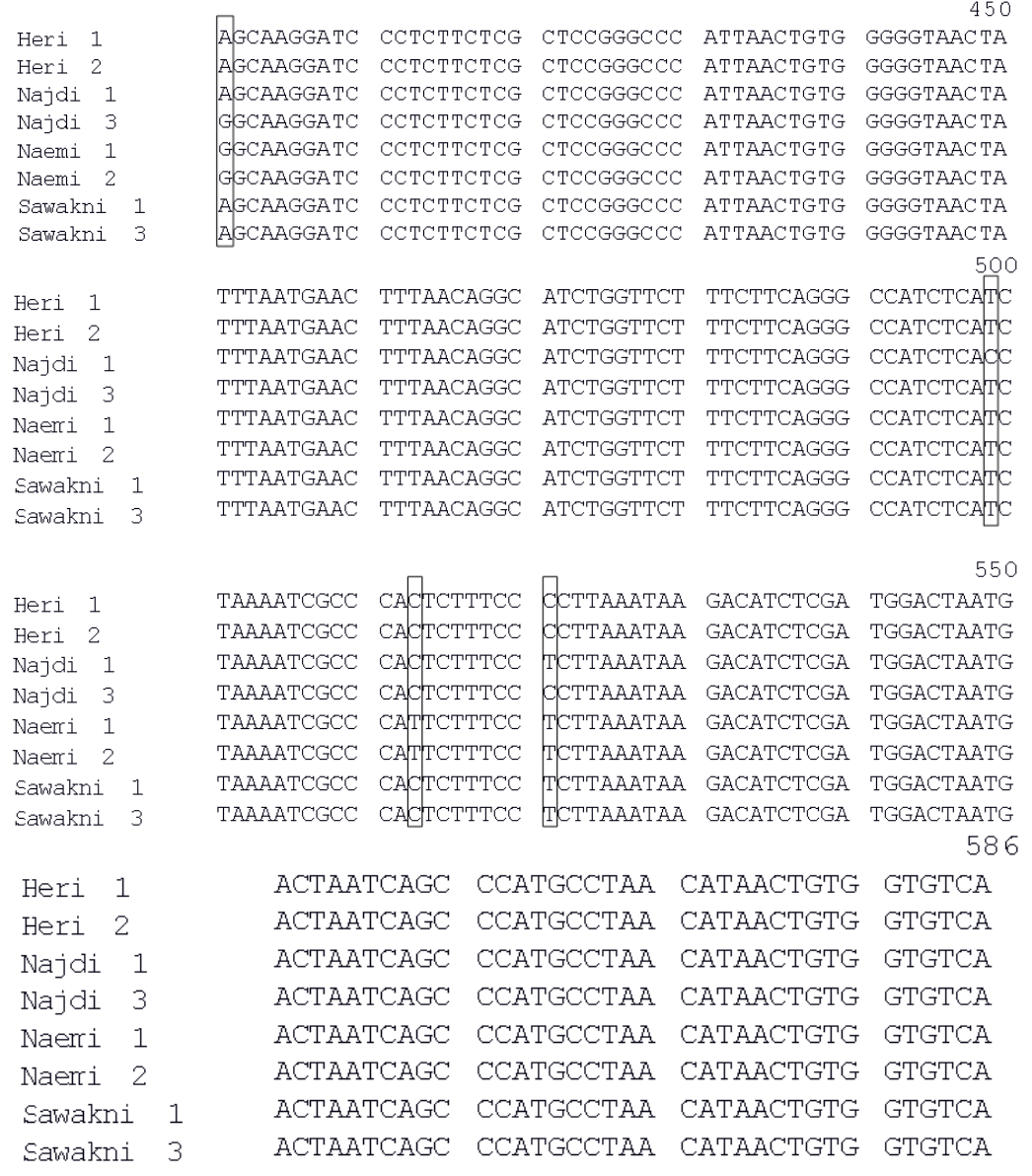

Fig. 5. The aligned nucleotides of the sequenced d-loop region for different indivduals of the studied sheep breeds. Note the high identity among the different samples. The letters inside the boxes are polymorphic among indivuduals and/or breeds. The underlined regions refer to the repeats (each sympol of the undelines refer to mirror image repeats of stems and loops)

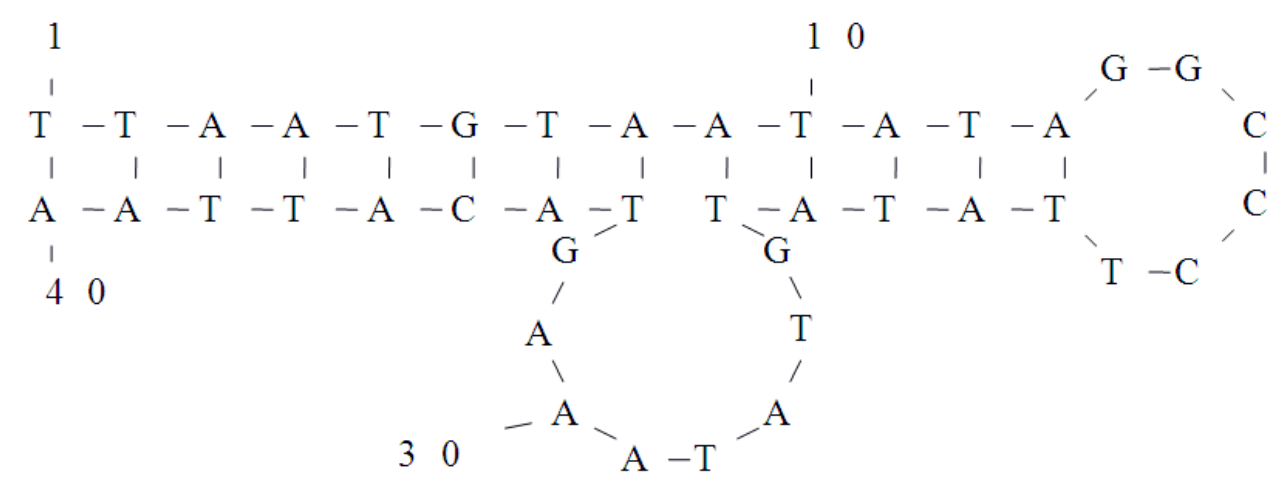

Fig. 6. Strong stem-and loop secondary structure of 40 bp inside 75 bp repeat region of sheep breeds d-loop sequenced in this study

The current breeds are belonging to the haplotype A containing the motif ACCCC or ACCTC. The sequenced fragment of the d-loop region showed 44 substitutions among breeds all of which are transitions except two 
changes in the first repeat which are transversion of adenine to cytosine. Most changes discriminated Naemi breed from others with some individual exceptions occurred in Najdi and Sawakni. The first change among the breeds was found at bases 30-34 (Fig. 6). These four bases can be considered as a key feature discriminating the four breeds from each other. It contains 3 gaps in Naemi, 1 gap in Najdi, GACC in Sawakni and GCCC in Heri. The constructed tree agreed with this finding in discriminating Naemi which came out of the cluster that is containing the other three breeds.

\section{DISCUSSION}

In the present study, four sheep breeds (Heri, Najdi, Naemi and Sawakni) were investigated biochemically and genetically by studying some metabolic isoenzymes and some mitochondrial DNA traits. The Arabian Najdi and Heri breeds are considered as native breeds. Naemi breed is also called the desert Awassi sheep in Saudi Arabia (Synnot, 1990). Sawakni breed might be the desert Sheep which belongs to seven breeds inhabiting the deserts of Sudan and Somali (El-Dirani et al., 2009).

Malate dehydrogenase catalyzes the following reversible reaction in the citric acid cycle: L-malate + $\mathrm{NAD}=$ oxaloacetate $+\mathrm{NADH}$, while malic enzyme reversibly catalyzes the oxidative decarboxylation of malate and is a link between the glycolytic pathway and the citric acid cycle: L-malate $+\mathrm{NADP}=$ pyruvate + $\mathrm{CO}_{2}+\mathrm{NADPH}$ (Shows et al., 1970; Song et al., 2001). It is therefore noteworthy to confirm that Malate Dehydrogenase $(M d h)$ is enzymatically and structurally distinct from malic enzyme (Shows et al., 1970). Each enzyme can be separated into a cytosolic and a mitochondrial molecular form by cellular location, physicochemical properties and gel electrophoresis (Hsu et al., 1967). Both enzymes are among the principal enzymes that are responsible for the NADPH production in ruminants (Laliotis et al., 2010). The first reaction (catalyzed by $M d h$ ) plays a key part in the malate/aspartate shuttle across the mitochondrial membrane and in the citric acid cycle (Minarik et al., 2002) while the second (catalyzed by Me) plays a role in lipid biosyntheses.

Minarik et al. (2002) stated that in eukaryotic cells, at least two forms of $M d h$ can be found. One isoform $(M d h-2)$ is a principal enzyme of the citric acid cycle operating within mitochondria. The other $(M d h-1)$ is found in the cytosol where it participates in the malate/aspartate shuttle. This shuttle exchanges reducing equivalent across the mitochondrial membranes in the form of malate/oxaloacetate. A third (Mdh-3) isoenzyme was found in the glyoxysomes of yeast, where it converts malate produced from glyoxylate in the glyoxylate cycle (Minard and McAlister-Henn, 1991). All Mdhs are NAD-dependent. The enzymes share a common catalytic mechanism and their kinetic properties are similar, which demonstrates a high degree of structural similarity.

Like goat (AL-Harbi and Amer, 2012), sheep breeds, in the present study, recorded three isoforms of $M d h$. The cytosolic $M d h-1$ was not shown in Naemi and Heri breeds but it was approximately detected in Najdi and Sawakni breeds and the mitochondrial $M d h-2$ was fixed in all breeds. As $M d h$ enzyme catalyses the reversible shuttle down of malate-oxalloactate pathway (Zhao et al., 2010) in the energetic citric acid cycle, it is therefore possible to elucidate that the metabolic rate of the Najdi and Sawakni breeds could be more energetic than the other two breeds.

In mammalian tissues three distinct isoforms have been described; a mitochondrial NAD-isoform and two NADP-dependent isoforms, a first localized in cytosol $(\mathrm{Me}-1)$ and a second occurred in mitochondria (Me-2). Cytosolic malic enzyme $(\mathrm{Me}-1)$ is considered as a NADPH-donor for fatty acid synthesis. It is also involved in the supply of fatty acids with the essential acetyl-coA. Acetyl-coA is produced in mitochondria but it is essential for fatty acids biosynthesis taking place in cytosol (Pearce, 1983). In ruminants, contrary to humans and rodents, the pathway of glucose-pyruvate-acetylcoA is of little significance, as the principal carbon source for lipogenesis instead of glucose, is the acetic acid produced by the rumen's microorganisms (Bergen and Mersmann, 2005). In sheep, unlike to other species, two transcripts encoding ovine $M e-1$ has been reported (Stefos et al., 2009), which may further elucidate possible explanations for the minor role of cytosolic malic enzyme in these species. It is therefore likely to expect the little expression of this enzyme in the studied breeds. The two fractions of Me showed expression in most of individuals of Heri and Naemi while the second fraction was found in all breeds. Since Me has a role in lipid biosynthesis (Zhang et al., 2007), it seems that Heri and Naemi breeds may possess more adaptability of lipid biosynthesis as these two breeds are more desert in their habitat than Sawakni and Najdi.

There was no variation in CO1 gene among all samples and breeds. CO1 data therefore supported the stability of this gene in all breeds studied. Cytochrome $\mathrm{C}$ oxidase is the terminal complex of the electron transport chain and is activated to prevent an excessive buildup of reactive oxygen species (Chen et al., 2009). It is also not affected by the variation in the respiratory capacity (Devin and Rigoulet, 2007). These two reasons may 
explain the similarity in the sequence of the gene coding for this protein in all sheep breeds. Ahmed et al. (2013) recorded similar finding for the Arabian camel.

Cytb gene also did not show any variation among the studied breeds. The hydrophilic protein of cytochrome $\mathrm{b}$ acquires higher mutations in abnormal cases of skeletal muscle weakness and exercise intolerance (Fernandez-Vizarra et al., 2007). It is one of the cytochromes which showed variations when the respiratory capacity changes (Devin and Rigoulet, 2007). It is therefore possible to correlate the identity in the sequence of this gene to the similarity in the respiratory capacity of different sheep breeds.

The only gene which showed slight variations among the breeds was ND4 gene. The inherited variation in mitochondrial genes (ND5 including ND4), in the absence of variation in the nuclear genome and other confounding factors, can influence glucose and lipid metabolism (Houstek et al., 2012). This may be in agreement with the variation in the isoenzyme pattern of both metabolic enzymes of $M d h$ and $M e$ and therefore the slight variations within this gene among the breeds may reflect some roles in lipid and glucose metabolism.

The analysis of the sequenced fragment of the d-loop region, in the present study, revealed that most individuals acquired three repeats (Heri and Naemi) and some acquired two repeats (Sawakni and Najdi). Hiendleder et al. (1998) found three, four and five repeats in the d-loop of two sheep haplotypes (A and $\mathrm{B})$. The discrepancy in repeat number between this study and that of the authors could be due to that, we sequenced partial part of the d-loop and this repeat is located near to the end of the d-loop. The proposed stem-loop structures within these repeats have been suggested as recognition sites for the arrest of $\mathrm{H}$ strand synthesis (Saccone et al., 1991).

Aside from three insertions/deletions and a single transversion, all variable nucleotide positions in sheep breeds control region represent transitions from $A$ to $G$ or $\mathrm{C}$ to $\mathrm{T}$ and vice versa. The variability among and within breeds was also recorded within these repeats and it was greater among breeds than within them indicating the efficiency of this molecular marker in discriminating among breeds. Such repeat has been described for other vertebrates in this region (Lunt et al., 1998; Brearley and Zhou, 2001) agreed with (Dionne et al., 1991; Rivera et al., 1997 ) in that there was no significant relationship between d-loop polymorphism and physiological performance. Based on these arguments, we could not able to relate the polymorphism in the d-loop repeat to the difference in physiological performance but to phenotypic differences among the studied breeds.

\section{CONCLUSION}

From the results, it could be concluded that the genetic variability among sheep breeds is very weak when we use the protein-coding genes where these genes are more impressive for the physiological role. The variability could be clearly addressed when the d-loop region was used where it controls the mtDNA replication. Isoenzymes discriminated clearly among the studied breeds although they are not as accurate as molecular tools indicating their applicability with more efficiency in physiology than in genetics. It is therefore necessary to recommend further molecular study using d-loop region in discriminating among Saudi Arabian sheep breeds and to conduct more isoenzymatic studies to address their physiological adaptations.

\section{REFERENCES}

Ahmed, M.M., S.A.M. El-Shazly, S.M.H. Sayed and S.A.M. Amer, 2013. Molecular study of energy related mitochondrial genes in Arabian and Bactrian camels. Am. J. Biochem. Biotechnol., 9: 61-70. DOI: 10.3844/ajbbsp.2013.61.70

AL-Harbi, M.S. and S.A.M. Amer, 2012. Preliminary comparative physiological and biochemical study of five different goat breeds inhabiting Saudi Arabia. Natur. Resou., 3: 206-212. DOI: 10.4236/nr.2012.34028

Ali, K.E. and A.A. Al-Noami, 1992. Copper status of Najdi sheep in eastern Saudi Arabia under penned and grazing conditions. Trop. Anim. Health Prod., 24: 115-120. PMID: 1305334

Almeida-Val, V.M.F., M.N. Paula-Silva, M.C.M. Caraciolo, L.S.B. Mesquita and I.P. Farias et al.,1992. LDH isozymes in amazon fish-III. Distribution patterns and functional properties in Serrasalmidae (Teleostei: Ostariophysi). Comparative Biochem. Physiol. Part B: Comparative Biochem., 103: 119125. DOI: 10.1016/0305-0491(92)90422-N

Bergen, W.G. and H.J. Mersmann, 2005. Comparative aspects of lipid metabolism: Impact on contemporary research and use of animal models. J. Nutr., 135: 2499-2502. PMID: 16251600

Brearley, M. and S. Zhou, 2001. Mitochondrial DNA and maximum oxygen consumption. Southern Cross University.

Bruford, M.W. and S.J. Townsend, 2006. Mitochondrial DNA Diversity in Modern sheep: Implications for Domestication. In: Documenting Domestication: New Genetic and Archaeological Paradigm, Zeder, M.A., D.G. Bradley, E. Emshwiller and B.D. Smith (Eds.), University of California Press, CA, USA., ISBN-10: 0520246381, pp: 307-317. 
Bruford, M.W., D.G. Bradley and G. Luikart, 2003. DNA markers reveal the complexity of livestock domestication. Nature Rev. Genetics, 4: 900-910. DOI: $10.1038 / \operatorname{nrg} 1203$

Chen, Y.F., C.H. Kao, Y.T. Chen, C.H. Wang and C.Y. Wu et al., 2009. Cisd2 deficiency drives premature aging and causes mitochondria-mediated defects in mice. Genes Dev., 23: 1183-1194. DOI: 10.1101/gad.1779509

Devin, A. and M. Rigoulet, 2007. Mechanisms of mitochondrial response to variations in energy demand in eukaryotic cells. Am. J. Physiol. Cell Physiol., 292: C52-C58. PMID: 16943247

Dionne, F.T., L. Turcotte, M.C. Thibault, M.R. Boulay and J.S. Skinner et al., 1991. Mitochondrial DNA sequence polymorphism, $\mathrm{VO} 2 \mathrm{max}$ and response to endurance training. Med. Sci. Sports Exerc., 23: 177-185. PMID: 1673216

El-Dirani, O.H., M.A. Jabbar and I.B. Babiker, 2009. Constraints in the Market Chains for Export of Sudanese Sheep and Sheep Meat to the Middle East. 1st Edn., Khartoum, ILRI (aka ILCA and ILRAD), ISBN-10: 9291461954, pp: 83.

Epstein, H., 1985. The Awassi Sheep with Special Reference to the Improved Dairy Type. 1st Edn., Rome, Italy, ISBN-10: 9251014140, pp: 57.

Fernandez-Vizarra, E., M. Bugiani, P. Goffrini, F. Carrara and L. Farina et al., 2007. Impaired complex III assembly associated with BCS1L gene mutations in isolated mitochondrial encephalopathy. Hum. Mol. Genet., 16: 1241-1252. PMID: 17403714

Guo, J., X. Du, H. Ma, J. Guan and B. Li, 2005. A novel maternal lineage revealed in sheep (Ovis aries). Anim. Genet., 36: 331-336. PMID: 16026344

Hiendleder, S., H. Lewalski, R. Wassmuth and A. Janke, 1998. The Complete mitochondrial DNA sequence of the domestic sheep (Ovis aries) and comparison with the other major Ovine haplotype. J. Mol. Evol., 47: 441-448. PMID: 9767689

Houstek, J., K. Hejzlarova, M. Vrbacky, Z. Drahota and V. Landa et al., 2012. Nonsynonymous variants in $\mathrm{mt}-\mathrm{Nd} 2, \mathrm{mt}-\mathrm{Nd} 4$ and $\mathrm{mt}-\mathrm{Nd} 5$ are linked to effects on oxidative phosphorylation and insulin sensitivity in rat conplastic strains. Physiol. Genomics, 44: 487494. DOI: 10.1152/physiolgenomics.00156.2011

Hsu, R.Y., H.A. Lardy and W.W. Cleland, 1967. Pigeon liver malic enzyme. V. Kinetic studies. J. Biol. Chem., 242: 5315-5322. PMID: 4383636

Lagana, G., E. Bellocco, C. Mannucci, U. Leuzzi and E. Tellone et al., 2006. Enzymatic urea adaptation: Lactate and malate dehydrogenase in elasmobranchs. Physiol. Res., 55: 675-688. PMID: 16497106
Laliotis, G.P., I. Bizelis and E. Rogdakis, 2010. Comparative approach of the de novo fatty acid synthesis (Lipogenesis) between ruminant and non ruminant mammalian species: From biochemical level to the main regulatory lipogenic genes. Curr. Genomics, 11: 168-183. DOI: 10.2174/138920210791110960

Lunt, D.H., L.E. Whipple and B.C. Hyman, 1998. Mitochondrial DNA Variable Number Tandem Repeats (VNTRs): Utility and problems in molecular ecology. Mol. Ecol., 7: 1441-1455. PMID: 9819900

Markert, C.L. and F. Moller, 1959. Multiple forms of enzymes tissue, ontogenetic and species specific pattern. Proc. Natural Acad. Sci. USA., 45: 753-763. PMCID: PMC222630

Minard, K.I. and L. McAlister-Henn, 1991. Isolation, nucleotide sequence analysis and disruption of the $\mathrm{MDH} 2$ gene from Saccharomyces cerevisiae: Evidence for three isozymes of yeast malate dehydrogenase. Mol. Cell Biol., 11: 370-380. PMCID: PMC359635

Minarik, P., N. Tomaskova, M. Kollarova and M. Antalík, 2002. Malate dehydrogenases--structure and function. Gen. Physiol. Biophys., 21: 257-265. PMID: 12537350

Paiva, S.R., V.C. Silverio, A.A. Egito, C. McManus and D.A. Faria et al., 2005. Genetic variability of the Brazilian hair sheep breeds. Pesquisa Agropecuaria Brasileira, 40: 887-893. DOI: 10.1590/S0100204X2005000900008

Pearce, J., 1983. Fatty acid synthesis in liver and adipose tissue. Proc. Nutr. Soc., 42: 263-271. DOI: 10.1079/PNS19830031

Pritchard, C.J.R., W.I. Robinson and J.B. Farnworth 1977. Feed intake, growth rate and lambing performance of a newly-established flock of desertbred Najdi sheep under an intensive yard-fed system. Ministry Agric. Water, Saudi Arabia, 1: 78-78.

Rivera, M.A., B. Wolfarth, F.T. Dionne, M. Chagnon and J.A. Simoneau et al., 1997. Three mitochondrial DNA restriction polymorphisms in elite endurance athletes and sedentary controls. Med. Sci. Sports Exeec., 30: 687-690. PMID: 9588609

Saccone, C., G. Pesole and E. Sbisa, 1991. The main regulatory region of mammalian mitochondrial DNA: Structure-function model and evolutionary pattern. J. Mol. Evol., 33: 83-91. PMID: 1909377

Scherf, B.D., 2000. World Watch List for Domestic Animal Diversity. 3rd Edn., Food and Agriculture Organization of the United Nations, Italy, ISBN-10: 9251045119, pp: 726. 
Shows, T.B., V.M. Chapman and F.H. Ruddle, 1970. Mitochondrial malate dehydrogenase and malic enzyme: Mendelian inherited electrophoretic variants in the mouse. Biochem. Genet., 4: 707-718. DOI: $10.1007 / \mathrm{BF} 00486384$

Song, Y., J. P. Wynn, Y. Li, D. Grantham and C. Ratledge, 2001. A pre-genetic study of the isoforms of malic enzyme associated with lipid accumulation in Mucor circinelloides. Microbiology, 147: 15071515. PMID: 11390681

Stefos, G.C., W. Becker, A.D. Lampidonis and E. Rogdakis, 2009. Cloning and functional characterization of the ovine malic enzyme promoter. Gene, 428: 36-40. DOI: 10.1016/j.gene.2008.09.027

Stegemann, H., A.M.R. Afify and K.R.F. Hussein, 1985. Identification of date (Phoenix dactylifera) cultivars by protein patterns. Phytochemistry, 26: 149-153. DOI: $10.1016 / \mathrm{S} 0031-9422(00) 81500-9$

Swofford, D.L., 2002. PAUP*. Phylogenetic Analysis Using Parsimony (*and Other Methods).
Synnot, W., 1990. Production data on desert bred Awassi sheep in a feedlot, Saudi Arabia. Proc. Aus. Soc. Anim. Prod., 18: 384-387.

Wendel, J.F. and N.F. Weeden, 1990. Visualization and Interpretation of Plant Isozymes, In: Isozymes in Plant Biology, Soltis, D.E. and P.S. Soltis (Eds.), Champan Hall, London, ISBN-10: 0412365006, pp: 5-45.

Yuncu, E., 2009. Mitochondrial DNA (mtDNA) haplogroup composition in Turkish sheep breeds. MSc, Thesis, Middle East Technical University.

Zhang, Y., P.I. Adams and C. Ratledge, 2007. Malic enzyme: The controlling activity for lipid production? Overexpression of malic enzyme in Mucor circinelloides leads to a 2.5-fold increase in lipid accumulation. Microbiology, 153: 2013-2025. PMID: 17600047

Zhao, S., W. Xu, W. Jiang, W. Yu and Y. Lin et al., 2010. Regulation of cellular metabolism by protein lysine acetylation. Science, 327: 1000-1004. DOI: 10.1126/science. 1179689 